\title{
La poca lectura de libros: Una trayectoria con dos sentidos
}

\author{
Elsa M. Ramírez Leyva *
}

Artículo recibido:

15 de diciembre de 2006.

Artículo aceptado:

11 de septiembre de 2007.

\section{RESUMEN}

El propósito de este artículo es proponer elementos para analizar las posibles causas de que la "poca lectura" sea considerada como uno de los problemas de la sociedad mexicana. La complejidad de la lectura necesita la formulación de otras posibles explicaciones distintas a las reduccionistas y determinantes relaciones socioeconómicas y educativas con las que se asocian las categorías estadísticas "esporádica," "poca" y "no" lectura de libros para poder explorar estas categorías identificadas en la Encuesta Nacional de Lectura del 2005 realizada por CONACULTA. Para ello nos apoyaremos en algunos de los criterios utilizados en los estudios cualitativos de corte sociológico que exploran el proceso diacrónico y sincrónico en la lectura de libros.

* Centro Universitario de Investigaciones Bibliotecológicas de la UNAM, México. eramirez@servidor.unam.mx INVESTIGACIÓN BIBLIOTECOLÓGICA, Vol. 22, Núm. 44, enero/abril, 2008, México,
ISSN: 0187-358X. pp. 33-64 
Palabras clave: Estudios de lectores; Poca lectura; Iletrismo; Prácticas de lectura.

\section{ABSTRACT}

\section{Poor or scarce reading. A two-way trajectory} Elsa M. Ramírez Leyva

New elements to analyse the possible causes of "scarce or poor reading", considered as one of the reading problems in Mexican society, are proposed. The paper explores the statistical categories ("sporadic", "little" and "none") identified by the National Reading Survey of 2005 realized by CONACULTA, arguing that the complexity of reading itself, needs explanations different from those based on determinant or reductionist arguments to explain socio-economic and educational relations. The criteria used are supported by qualitative studies of a sociological nature which explore the diachronic and synchronic processes in the reading of books.

Keywords: Reader studies; Scarce reading; Illiteracy; Reading practices.

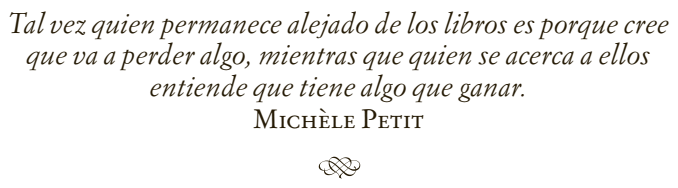

\section{INTRODUCCIÓN}

$\mathrm{H}$ oy en día, no leer libros o hacerlo sólo de manera esporádica se considera una práctica inadmisible o, para decirlo en otras palabras, una falla de las comunidades letradas, las cuales pretenden que sus ciudadanos reúnan los requisitos que la caracterizarían como lectores asiduos o frecuentes. Tal convicción responde a las tipologías de los comportamientos lectores construidos a partir de criterios cuantitativos, como es el número de libros leídos -aparte de otro tipo de materiales, como diarios, revistas y medios digitales. Desde luego lectora es, en principio, toda persona que se ha apropiado del alfabeto, pues mediante éste asegura su acceso a la cultura escrita. Sin embargo, las representaciones que se forman los alfabetizados y las prácticas de lectura 
que adoptan son distintas y por ello es posible identificar colectivos heterogéneos agrupables según sus capacidades, y también por las representaciones y prácticas de lectura.

En este artículo nos orientaremos específicamente a analizar de manera concreta las prácticas de lectura que corresponden a las categorías "no lectura", "lectura esporádica" o "poca lectura" de libros, estas dos últimas las consideramos equivalentes y algunos otros autores las denominan precarias, concepto que no utilizamos porque remite no sólo a la cantidad sino también a la calidad de los contenidos que se consumen. Es oportuno aclarar que la categoría específica de "no lector" corresponde a quien no lee libros, aunque podría frecuentar textos en otros soportes como diarios, revistas e historietas. Para tal fin, nos basaremos en la reciente Encuesta Nacional de Lectura aplicada a fines de 2005, primera en su tipo que se realiza en México. El propósito de este análisis es formular otras posibles explicaciones distintas de las reduccionistas y determinantes relaciones socioeconómicas y educativas con que se asocian las categorías estadísticas "esporádica," "poca” y "no" lectura de libros. Para ello nos apoyaremos en algunos de los criterios utilizados en los estudios cualitativos que exploran el proceso diacrónico y sincrónico de la conformación de representaciones y prácticas de lectura.

La Encuesta a la que nos hemos referido ofrece una tipología de lectores configurada por diez categorías resultado de las relaciones entre perfiles socioeconómicos, geográficos y escolares, por un lado, y, por lo otro manifestaciones cuantitativas de las preferencias: la cantidad de libros y otros materiales leídos durante el último año. Al mismo tiempo, incluye otros factores que intervienen en la formación de las prácticas lectoras y que resultan útiles para analizar una parte de la evolución de prácticas correspondientes a las categorías "no", "poca” o "esporádica" lectura de libros. La Encuesta Nacional de Lectura da cuenta de ello y nos ofrece así indicios importantes para conocer una cierta realidad subterránea cuya superficie, no obstante, resulta visible como para explicar de qué modo se conforman las prácticas de lectura de los mexicanos.

La caracterización de lectores que proponemos la conforman seis tipos en lugar de las diez tipologías (éstas aparecen indicadas entre paréntesis), pero que a nuestro juicio son equivalentes a las nomenclaturas dadas en la Encuesta Nacional de Lectura: ${ }^{1}$

A. Extensivo (Lector frecuenta libros y publicaciones diversas).

B. Lector literario (Lector frecuente de literatura y preferencialmente de literatura). 
C. Intensivo temático o tipo de publicación (Lector preferencialmente de periódicos y de revistas).

D. Escolar (Lector preferencialmente de libros para la escuela y escolar diversificado).

E. Esporádico (Lector esporádico).

F. No lector (Poco lector).

En cuanto a los aspectos teóricos en que se sustentan las categorías de "no lectura" "poca lectura o esporádica", consideramos pertinente tomar en cuenta algunos aspectos cualitativos que ampliarán la perspectiva para observar la trayectoria de esas categorías, y que contribuirán a comprender cómo se configuran tales categorías, y además aportarán ideas para validar y complementar el criterio puramente cuantitativo.

\section{SOBRE LA FUENTE DE INFORMACIÓN}

La fuente de datos en que se basa nuestro análisis es la Encuesta Nacional de Lectura (ENL), editada por CONACULTA y destinada a conocer específicamente el estado en que se encuentran las prácticas sociales de lectura de la población mexicana, por lo que examina un espectro muy amplio de los factores que intervienen en la formación de lectores. Los datos de esta fuente reúnen las siguientes características:

1. Abarcan todo el país.

2. Se obtuvieron gracias a métodos rigurosos aplicados en una muestra diseñada científicamente, y por ello resultan muy confiables.

3. Aportan elementos que pueden considerarse cualitativos.

\section{EL LIBRO METONÍMICO DE LA LECTURA}

No desconocemos que hoy en día los materiales de lectura son muy diversos, tanto temática como genéricamente. Sin embargo, consideramos justificado preferir entre todos ellos a los libros, porque constituyen un símbolo universal de la cultura escrita: son la materialización escrita de ideas, emociones, conocimientos, informaciones y valores generados por la humanidad, y en virtud de ello vienen a constituir una construcción social tangible. El libro y la lectura resultan un efecto de la escritura, pero lo son de un modo especial. En su origen, la palabra escrita se asociaba con la palabra de la divinidad, y 
ello la revestía de una triple sustancia: autoridad, venerabilidad y verdad. Por consecuencia, el texto adquiría estatuto de ley, de enseñanza y de guía. Desplazamientos cualitativos vinculados con la metonimia y con la contigüidad entre escritura, lectura, lector y libros les confieren a estos últimos un simbolismo y un ascendiente de gran importancia en la cultura.

Aunque en los tiempos modernos al libro se le reserva un lugar muy distinto, su complejo y alto valor simbólico sobrevive en el imaginario social, pues, como es posible observar en la siguiente gráfica, predomina en relación con otros materiales y se le considera parámetro cuantitativo para definir las tipologías de lectores.

\section{¿Usted lee...?}

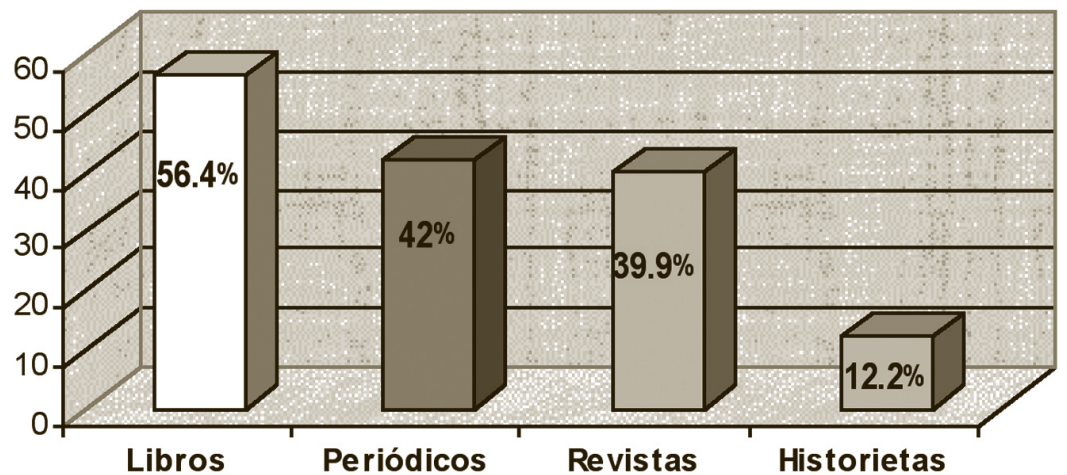

Fuente: Encuesta Nacional de Lectura. México: CONACULTA, 2006. p. 19.

McKenzie señala que el libro es un instrumento expresivo donde se conjugan la forma, la función y el significado simbólico; por tanto, tiene un efecto social, pues en la interacción con los textos intervienen la producción, la transmisión y el consumo. ${ }^{2}$ De igual manera, Chartier señala que los libros están cargados de significaciones diferentes y cambiantes que se construyen en el marco de una propuesta y una recepción. Los sentidos atribuidos a sus formas y a sus motivos dependen de las competencias o de las expectativas de los diferentes públicos que se adueñan de ellas. ${ }^{3}$ La manera de estar presente o ausente entre los grupos se articula con las diferencias sociales, aunque también con las diferentes circunstancias en los trayectos de la vida lectora. Respecto al estatuto que posee el libro en la sociedad mexicana, ésta se encuentra

2 D.F. McKenzie, Bibliography and the Sociology of Texts. Londres: The British Library, 1986, p. 3

3 Roger Chartier, El orden de los libros: lectores, autores y bibliotecas en Europa entre los siglos XIVy XVIII, Barcelona: Gedisa, 1994, p. 21 
en las primeras elecciones de los encuestados cuando se les pidió relacionar lectura y lector, como lo podemos apreciar en las siguientes gráficas:

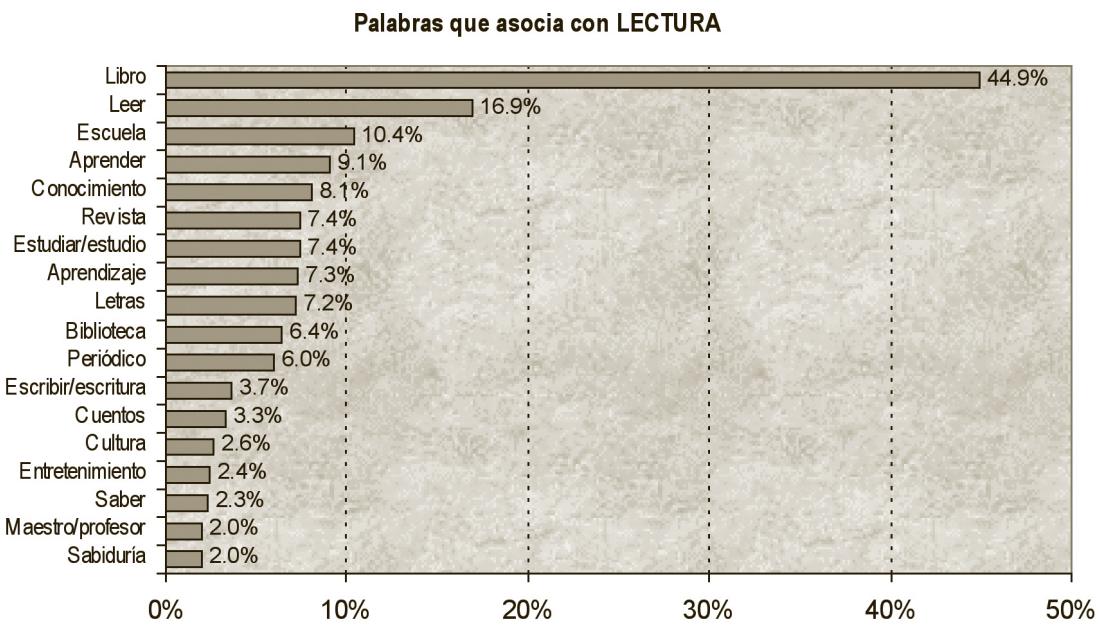

Fuente: Encuesta Nacional de Lectura. México: CONACULTA, 2006. p. 84

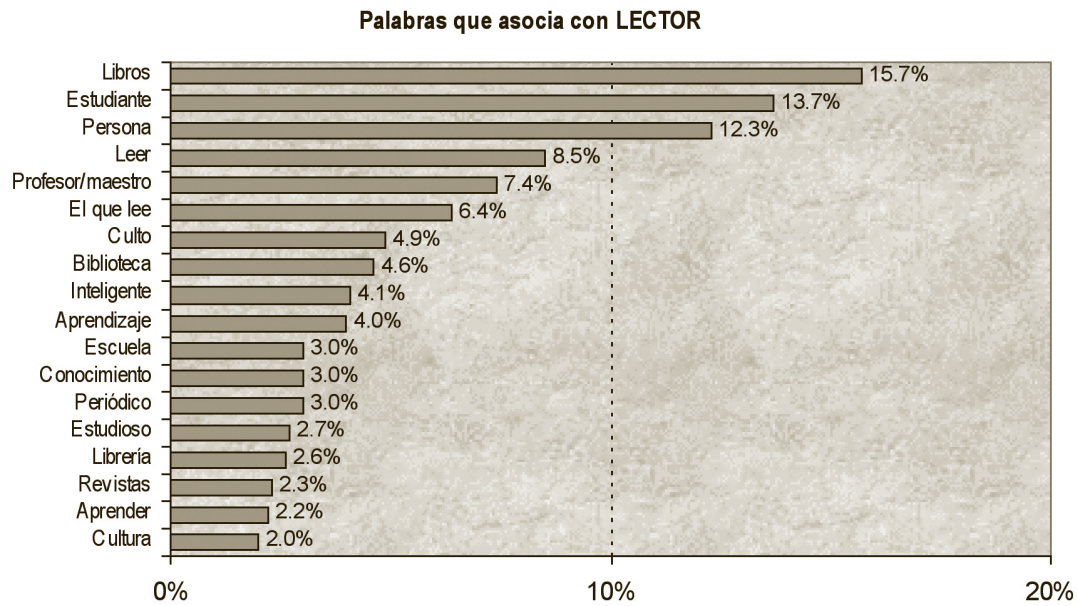

Fuente: Encuesta Nacional de Lectura. México: CONACULTA, 2006, p. 85.

Estos datos confirman que el libro, como señala Peroni, es el soporte por excelencia de una definición legítima de la lectura. ${ }^{4}$ Pero también es el estereotipo de la lectura culta, es decir el objeto por excelencia de la cultura 
escrita. Así, según las gráficas, parece que la actividad lectora y el sujeto que la realiza alcanzan su más acabada definición cuando se centran en el libro, sin importar que se trate de estudiar o aprender, cumplir en la escuela, elevar la cultura o afinar la inteligencia. Pero también se advierte en esas menciones que el placer, el entretenimiento y el disfrute en apariencia no se relacionan con la lectura. Las representaciones simbólicas consideradas en las tablas anteriores pueden determinar de manera temporal o definitiva la relación con la lectura y con el libro. Puesto que la lectura remite a los libros, los buenos lectores, que leen suficientes libros en cantidad y calidad, son más cultos, y se les coloca en un lugar muy próximo al supuesto saber. Nada se piensa respecto a sí la lectura se realiza bien o mal, y la valoración de ella se vincula simplemente con su ejecución mecánica y con un plano de interpretación literal, tal como suele ponderarse la lectura escolarizada.

El libro se asocia pues, metonímicamente, con la lectura, y también con el lector. Las representaciones de ambos y las prácticas de la lectura se conforman o reconfiguran a partir de los usos del libro, puesto que éste opera como un referente dotado de significado variable según las circunstancias, y podríamos decir que el lector es efecto de ellas. Hay personas que, unas veces por vía directa y otras indirecta -al mirar a alguien que leía-, establecieron un vínculo como lectores con su primer objeto de lectura, que pudo haber sido una historieta o un diario, y que posteriormente emprendieron el pasaje a la lectura de libros. Ello, porque el libro es un objeto simbólico que ocupa un lugar de larga data en la sociedad y que, como objeto simbólico, se inserta, según Thompson, en los contextos y procesos sociohistóricos en los cuales y por medio de los cuales se produce, transmite y recibe el propio libro. ${ }^{5}$ Además, las prácticas lectoras dependen de los diferentes niveles de acceso -recursos y oportunidades-al libro, y de los diferentes espacios disponibles para realizar la lectura.

Por otra parte, la sobrevaloración del libro se extiende a quienes leen o poseen libros, lo cual tiene un antecedente histórico: una difundida actitud reverencial ante él, muy bien ilustrada en la pintura $\operatorname{Der} G r u \beta$ (El saludo), de Quint Buchholz. ${ }^{6}$

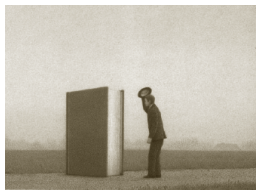

5 John B. Thompson, "La concepción simbólica y la concepción estructural de la cultura", en Teoría y análisis de la cultura / comp. Gilberto Giménez Montiel, México: Universidad de Guadalajara, DGICSA, 1980, p. 348. Este autor señala cinco aspectos de la constitución de las formas simbólicas: intencional, convencional, estructural, referencial (estos cuatro transmitidos por medio del significado, el sentido) y contextual (determinado por las características espaciales y temporales de la producción, transmisión y apropiación de las formas simbólicas). 
De ello se deriva que las categorías de lectores y las prácticas de lectura se formulen a partir del criterio cuantitativo de la lectura y de la posesión de libros. Sin embargo, evidentemente, semejante pauta puede distorsionar la realidad, puesto que para leer un solo libro, en un tiempo determinado y en ciertas circunstancias, un lector podría tener que sortear más obstáculos que otros lectores cuyo medio resulta más favorable para la lectura. $\mathrm{O}$ bien, la lectura de un solo libro, por haber modificado sustancialmente la vida o la relación del lector con su mundo exterior, podría considerarse de importancia superior a la lectura, en todo un año, de varios libros cuyo efecto es nulo. Asimismo, en las trayectorias de lectura pueden efectuarse cambios significativos en la forma de relacionarse con los libros y con la lectura. Otro aspecto que debe considerarse, por último, es la posible valoración distinta del libro, como símbolo, entre representantes de diversas generaciones de jóvenes o entre miembros de comunidades sociales que se vinculan de modo también diferente con la palabra escrita. Ello reviste especial importancia hoy, cuando los medios audiovisuales y digitales, así como atractivas e innumerables publicaciones periódicas, colocan al libro en un territorio diferente, porque ya no es el único ni el más importante soporte de los textos, sino sólo uno más, como podremos constatar más adelante.

En el México actual, la oferta y el acceso a la lectura se han extendido como nunca había ocurrido en épocas anteriores. Así lo prueban el creciente mercado de ediciones nacionales e internacionales y la multiplicación de espacios de lectura, como bibliotecas y salas destinadas a esa actividad. Asimismo, puede hablarse de una vasta pluralidad de públicos reales y potenciales de lectores, puesto que $92 \%$ de la población se encuentra alfabetizada y se registra un proceso ascendente de la escolarización, que hoy alcanza 8.1 años en promedio, cuando en 1990 sólo llegaba a 6.6 años. Por otro lado, en el presente, el $17.9 \%$ de los mexicanos ha concluido la primaria, el $21.5 \%$ la secundaria, y la escolaridad en la escuela media superior es del $19.5 \%$ y en la superior del $13.1 \% .^{7}$

Pese a todo lo anterior, conforme a los resultados de la Encuesta Nacional de Lectores, el $43.6 \%$ de la sociedad letrada declara no leer libros, el $12.7 \%$ afirma que nunca ha leído libros y el $30.4 \%$ considera que lee pocos libros, y se ubica por tanto en el grupo de lectores esporádicos donde se incluye al lector intensivo, pues su preferencia lectora se dirige a diarios, revistas e historietas, como se observa en el siguiente cuadro.

7 Estadísticas proporcionadas por INEGI, correspondientes a 2005. <http://www.inegi.gob.mx/ est/contenidos/espanol/rutinas/ept.asp?t=medu09\&c=3277> 


\begin{tabular}{|ll|c|c|c|}
\hline & Tipo de lector & $\%$ & Lecturas principales & Número de libros leídos al año \\
\hline A & Extensivo & 9.0 & Libros de diferentes temas & 6.44 \\
\hline B & Literario & 10.4 & Libros de literatura & de 3.9 a 6.52 \\
\hline C & $\begin{array}{l}\text { Intensivo, } \\
\text { poco lector de libros }\end{array}$ & 30.6 & Diarios y revistas mensuales & $\begin{array}{c}\text { de } 1.15 \text { a } 2.8 \text { (sólo los lee } \\
46.8 \% \text { ) }\end{array}$ \\
\hline D & Escolar & 19.5 & Libros de texto & de 4.32 a 5.77 \\
\hline E & $\begin{array}{l}\text { Esporádico, poco } \\
\text { lector de libros }\end{array}$ & 19 & $\begin{array}{c}\text { Algo de literatura y textos } \\
\text { escolares }\end{array}$ & 1.2 (sólo los lee 24.2\%) \\
\hline F & No lector & 11.4 & No lee libros & 0.08 \\
\hline
\end{tabular}

Esta situación se relaciona con factores económicos y educativos, aunque éstos no son los únicos que determinan los lazos entre sociedad, libros y lectura. Al respecto, algunos estudios de corte cualitativo advierten sobre un fenómeno que aparece aun en países desarrollados, el iletrismo, en el que concurren la declinación en la lectura de libros, notorias desigualdades en las destrezas lectoras y un progresivo empobrecimiento del capital lingüístico y cultural de las personas. Tales hechos se deben en parte a que ni la familia ni los sistemas educativos, incluidas las bibliotecas tradicionales, han logrado alentar prácticas que desarrollen competencias y actitudes lectoras suficientes las cuales serían indispensables para revertir la tendencia histórica de muchos grupos a apartarse progresivamente de los libros pese a encontrarse alfabetizados. Así, en el marco de un desigual acceso a la calidad de servicios bibliotecarios y materiales de lectura, y ante un papel disfuncional de la familia al respecto en cuanto a transmitir la práctica de la lectura, cada vez más personas se orientan hacia un contacto con los libros circunscrito al ámbito meramente escolar, y la formación de prácticas permanentes de lectura de libros es más débil. Por otro lado, la biblioteca necesita hacer un gran esfuerzo para equilibrar el poder del mercado, el que favorece el consumo de libros cuya lectura no implica ningún esfuerzo intelectual. Encima de todo, una numerosa y variada oferta de información y materiales escritos, impresos o en formato digital, destinados a actividades de aprendizaje, entretenimiento y placer, se encuentran bajo el dominio de empresas cada vez más influyentes que se introducen en las redes sociales, ahora globalizadas, y obtienen cuantiosas ganancias económicas en tiempos breves, a cambio de productos de dudosa calidad.

\section{LAS TRAYECTORIAS DE LECTURA}

Las encuestas y, en particular, los estudios cualitativos sobre la lectura se consideran una conquista importante en los círculos políticos, académicos y 
culturales, lo cual revela un creciente interés por conocer la complejidad y la pluralidad de las prácticas de lectura. En tanto que las prospecciones históricas y cualitativas de la lectura han adoptado métodos sociológicos, etnográficos, psicoanalíticos y psicológicos que conciben la lectura como un hecho social, se ha llegado a considerar que las representaciones y prácticas relacionadas con esa actividad son diferentes. En el marco de un amplio proceso de desarrollo, en esas indagaciones se han incorporado herramientas como las narraciones o historias de vida.

Estas consideraciones las encontramos, entre otras, en las pesquisas de J. Bahloul respecto de las categorías denominadas "no lector", "poco lector" o "lector esporádico" de libros, pues las biografías se distinguen por la posición del lector en la jerarquía social y por su nivel de instrucción, particularidades que ofrecen información acerca de escenarios de lectura y representaciones del libro, de la lectura y del lector. Asimismo, esas variables informan sobre los modelos de clasificación de géneros y de la adquisición de libros, sobre la socialización del lugar asignado tanto al libro como a la lectura en las prácticas culturales y sobre el proceso formativo del lector que está a cargo de la familia. ${ }^{8}$ La misma Bahloul busca la función diacrónica en las biografías, ahí donde el escenario de lectura es el conjunto de las condiciones sociales derivadas de la historia familiar, socioprofesional y educativa de los lectores. Esas trayectorias pueden seguir un proceso evolutivo y modificarse en su itinerario:

la posición de "poco lectores" aparece más como el punto de una trayectoria compleja que como el resultado de disposiciones sociales determinadas e inmutables. Por esta razón, el grupo de los "poco lectores” no constituye ni un hábito cultural sistematizado, ni una categoría sociológica específica dotada de un capital cultural y económico característico. Aunque claramente representados en ciertas categorías, los "poco lectores" abarcan un amplio rango de la escala social y distintas trayectorias culturales, profesionales y geográficas. A lo sumo se caracterizan, en su relación con la lectura, por su conjunto de condiciones prácticas y sociales, que pueden estar determinadas por un modelo estructural. ${ }^{9}$

De esta autora destacaremos el señalamiento relativo al conjunto de condiciones prácticas y sociales determinadas por un modelo estructural, pues precisamente la autora se resiste a considerar que las prácticas de lectura constituyan un hábito cultural sistematizado resultante de disposiciones

8 Joëlle Bahloul, Lecturas precarias. Estudio sociológico sobre los "poco lectores", México: FCE, 2002, p. 22 
sociales determinadas, ${ }^{10}$ y además indica que la lectura está implicada en la organización y las condiciones sociales. Por tanto, es necesario explorar el tejido social en que se despliegan las representaciones y las prácticas de la lectura, es decir el escenario donde la apropiación del capital libresco se articula desde la relación material con el libro, a partir del lugar que esto ocupa y la función que desempeña en el contexto social, así como del carácter ideológico y social que tiene la lectura. En vista de esa articulación, la "no lectura" y la "poca" o "esporádica lectura" pueden legitimarse en ciertos casos, en ciertos momentos de las biografías, como lo puntualiza Bahloul al referirse al fortalecimiento de la "poca" o la "esporádica lectura" causada por la disminución de la "no lectura" de libros. Pensemos en el proceso de iniciación de los jóvenes o adultos recién alfabetizados que comienzan a familiarizarse con los libros y en ciertas circunstancias propicias para que se incorporen en el mundo libresco.

Por su parte, otro estudioso del tema, Michel Peroni, presenta otro enfoque y señala que no es común problematizar los supuestos atributos positivos y normativos de la lectura, los cuales rigen los criterios con que se estiman la práctica y las representaciones de ella. Esos supuestos conforman el modelo con que se mide la eficacia de la imposición de una práctica acerca del uso legítimo de las producciones culturales. Peroni considera la lectura como una operación doble de construcción social de la realidad, la cual puede leerse, y al mismo tiempo vincularse con ella, con el sentido del acto de leer y con la situación en que este acto se inscribe. En sus estudios sobre trayectorias de lectura, el mismo autor propone sustituir la problemática de la imposición con la de la apropiación como una acción social. Según él, las categorías "no lector" y "poco" o "esporádico lector" tienen sentido en una perspectiva lineal, diacrónica, en donde se produce un continuum entre esas categorías y las de lectores buenos, frecuentes o extensivos; es decir, cuando debido a un proceso de fortalecimiento de la lectura, los "poco" o "esporádicos" lectores aumentan en la medida en que se reducen los no lectores. Falta determinar también, sin embargo, si a esta última categoría se remiten los lectores frecuentes que han disminuido la cantidad y frecuencia de lectura de libros, lo cual hablaría de un debilitamiento de la lectura. Por tanto, según Peroni, más que corroborar el iletrismo, la incompetencia o la resistencia a la lectura, conviene interrogarse sobre las modalidades de la lectura "esporádica" o "poca". Para ello, será preciso considerar las trayectorias de lectura desde una perspectiva sincrónica y como resultado de una conexión entre prácticas y significaciones en un contexto, aunque reinterpretadas en relación con un 
tiempo y un lugar diferentes al original, pues ciertas transformaciones pueden acarrear diferencias significativas respecto de un tiempo presente. ${ }^{11}$

Michèle Petit, otra de las especialistas de la lectura, señala que la lectura asidua, no supone que las prácticas de lectura sean una cuestión de herencia, de consumo socialmente programado. ${ }^{12}$ Asimismo, afirma que, por lo general, la lectura pasa poco a poco de ser una actividad en un principio proscrita a convertirse en un gesto efectuado voluntariamente. Así, esta autora también la ubica en un trayecto de vida, donde una biblioteca o la lectura misma pueden recomponer la identidad lectora puesto que ésta sigue un proceso aún inconcluso. Petit considera además que los trayectos son una especie de rompecabezas y no algo que evoluciona de manera lineal, puesto que en los acercamientos a la lectura intervienen factores sociales, familiares y psíquicos que en ocasiones pueden convertirse incluso en obstáculos para la lectura. Eso es lo que ocurre, por ejemplo, con los miembros de ciertos sectores sociales a quienes no les resulta clara la utilidad de la lectura y llegan a considerarla como una pérdida de tiempo. En otros casos, cuando tiene lugar la identificación primaria propia de la infancia, tanto en la familia como en el grupo social, la lectura de libros viene a ser una forma de autoexclusión opuesta al deseo de integrarse, y termina por quedar proscrita.

Por otro lado, una de las aportaciones originales de Petit es el enfoque psicoanalítico que emplea y que nos coloca en la dimensión psíquica de los vínculos afectivos desplazados y anudados a objetos y a actividades culturales: el libro y la lectura simbolizan tanto unión como separación, pero garantizan continuidad. Asimismo, la lectura es una forma de sublimación de los afectos primordiales y da lugar a procesos de identificación con otros (los personajes). El libro propicia afectos y suscita rechazos. Por otra parte, la misma Petit señala que la lectura puede despertar temor porque implica un trayecto hacia el interior del lector. Por ello cita esta reflexión de la psicoanalista inglesa Melanie Klein: "Leer significa para el inconsciente tomar la ciencia del interior del cuerpo de la madre", idea con la que coincide el historiador de la lectura Alberto Manguel. ${ }^{13}$

Petit explica toda esta relación entre lector, libro y lectura con el fin de desvelar su complejidad, en contraste con las concepciones reductoras o aquellas que juzgan como concluyente una parte del trayecto en la vida de un lector. No sólo la escolarización insuficiente o un ineficiente papel de la biblioteca intervienen en la formación de lectores y en la transmisión del gusto por leer, sino también afectos que permiten una identificación con el libro y

11 Peroni, op. cit., p. 27 y ss.

12 Michèle Petit, Nuevos acercamientos a los jóvenes y a la lectura. México: FCE, 1999, p. 17 
la lectura en el medio familiar y en el contexto social, además de circunstancias fortuitas capaces de modificar trayectorias que podrían pensarse determinadas para siempre e irrenunciables.

Por su parte, Bernard Lahire, sociólogo de la lectura, nos recuerda que las reflexiones sobre desigualdades sociales respecto al material impreso, en especial el libro, son necesarias, pues no ha de olvidarse que la lectura no es una práctica homogénea en todos los lugares y espacios sociales. Aunque los estudios cuantitativos revelaran que progresivamente, por el número de libros leídos, se reducen las brechas entre "no lectores", "lectores esporádicos" o "poco lectores" y "lectores asiduos", deberá tomarse en cuenta que no sólo ese aspecto reviste importancia, pues la poseen igual los géneros frecuentados y aun las experiencias y transformaciones personales ocurridas por efecto de las lecturas. Asimismo, Lahire señala que las obras son objeto de diferentes usos e investiduras sociales, a veces de carácter opuesto o contradictorio. Ciertos libros pueden ser actualizables para algunos lectores, mientras que para otros tal intento podría resultar una operación difícil y desalentaría la lectura; por tanto, más que marcar fronteras, considera más importante reconstruir las diferentes experiencias de los lectores con obras de distintas categorías, por más que se sigan usando como complemento los estudios cuantitativos o bien se busque la manera de aprovechar los resultados de las encuestas.

Conviene tomar en cuenta otros aspectos que distorsionan la realidad de las prácticas de la lectura, como lo revelan los estudios cualitativos emprendidos por investigadores como Olivier Donnat, Christine Détrez, Anne-Marie Chartier y Gérard Mauger, entre otros, quienes coinciden en que toda investigación o encuesta debe estar presidida por esta pregunta fundamental: ¿qué se entiende por lectura? Ello, porque parte de las equivocaciones surgen a causa de malentendidos o de la suposición de que todo investigador parte del mismo concepto de lectura y tiene idéntica representación social del libro. Los autores citados recomiendan también tener presentes los aspectos que ocultan o distorsionan la relación entre las prácticas de lectura y lo que se declara acerca de ellas, pues, por ejemplo, el olvido, la noción de legitimidad de las lecturas -según las cuales cierto tipo de textos podrían considerarse tan triviales que no merecería la pena mencionarlos como material de lectura- o bien la confusión entre la lectura, por un lado, y, por otro, el estudio, el trabajo y las actividades religiosas, domésticas y deportivas podrían tergiversar los resultados de una investigación. Tampoco habrán de perderse de vista los aspectos generacionales, ya que es bien sabido que al capital cultural de los jóvenes de hoy está incorporada la tecnología digital así como al de los lectores de la generación anterior lo estuvo el televisor, y 
que eso constituye una diferencia notable respecto de los lectores de épocas anteriores, para los que el libro significó la única, y tal vez por eso invaluable, conquista. Al mismo tiempo, influyen los diferentes modos de transmitir los comportamientos lectores y de mediar en ellos, a la vez que las posibilidades de acceso y la disponibilidad de los libros.

A la disciplina bibliotecológica, lo anterior le permite analizar la "no lectura" y la "poca" o "esporádica lectura" desde tres perspectivas: a) el fortalecimiento progresivo de la práctica de lectura de libros o, en su defecto, su debilitamiento, ocasionado por un proceso de iletrismo y un desplazamiento de la lectura de libros hacia otros medios impresos y digitales, o tal vez un acceso a los libros o una disponibilidad más restringida a ellos; b) la mediación de la biblioteca, que puede modificar las trayectorias de los lectores en alguna de las dos direcciones y c) la lectura y el libro como modos de inclusión o exclusión social.

\section{LOS NO LECTORES DE LIBROS}

La categoría de "no lectores de libros", de acuerdo con los datos ofrecidos por la Encuesta Nacional de Lectura, representa el 43.6\% del total de los encuestados y se divide en dos grupos: poco menos de la tercera parte $(30.4 \%)$ reportó haber leído libros en algún momento de su vida, en tanto que el 12.7\% declaró no haber leído nunca libros.

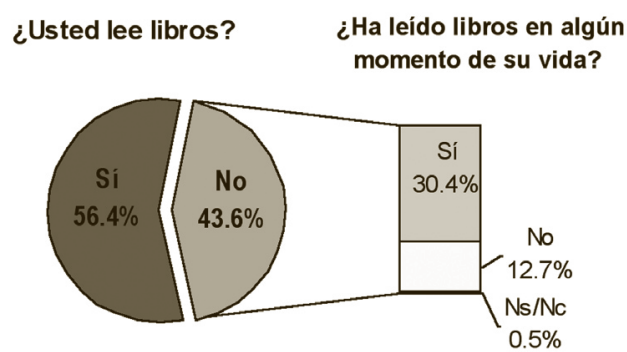

(Ns: no sabe; Nc: no contestó)

Fuente: Encuesta Nacional de Lectura, México, CONACULTA, 2006, p. 19

La distribución de los "no lectores" es la siguiente: 


\begin{tabular}{|c|c|c|c|}
\hline \multicolumn{4}{|c|}{ ¿Ha leído libros en algún momento de su vida? } \\
\hline & & No & Sí \\
\hline Nacional & & 12.7 & 30.4 \\
\hline \multirow{2}{*}{ Sexo } & Hombre & 11.1 & 31.3 \\
\hline & Mujer & 14.0 & 29.7 \\
\hline \multirow{6}{*}{ Edad } & 12-17 años & 6.4 & 26.8 \\
\hline & 18-22 años & 8.2 & 21.2 \\
\hline & 23-30 años & 13.2 & 33.9 \\
\hline & $31-45$ años & 9.1 & 36.1 \\
\hline & 46-55 años & 20.8 & 26.1 \\
\hline & 56 años o más & 25.2 & 32.1 \\
\hline \multirow{5}{*}{ Escolaridad } & Ninguna & 44.0 & 31.1 \\
\hline & Primaria & 22.4 & 33.5 \\
\hline & Secundaria & 10.0 & 34.2 \\
\hline & Bachillerato & 9.5 & 30.0 \\
\hline & $\begin{array}{l}\text { Universidad } 0 \\
\text { más }\end{array}$ & 1.9 & 20.5 \\
\hline \multirow{5}{*}{$\begin{array}{c}\text { Nivel } \\
\text { socioeconómico }\end{array}$} & Muy bajo & 20.4 & 41.1 \\
\hline & Bajo & 17.7 & 33.1 \\
\hline & Medio bajo & 11.0 & 31.8 \\
\hline & Medio & 4.1 & 16.7 \\
\hline & Medio alto/Alto & 1.4 & 20.2 \\
\hline
\end{tabular}

Fuente: Encuesta Nacional de Lectura. México: CONACULTA, 2006. p. 20

Como puede observarse, los mayores porcentajes de quienes nunca han leído libros se ubican en una línea generacional que va de los 23 a los 30 años y de 56 en adelante, sin escolaridad y en niveles socioeconómicos bajo y muy bajo. Llama la atención que tal circunstancia, aunque en porcentajes menores, se repita con los encuestados de niveles de escolaridad primaria, secundaria, bachillerato y universidad, pese a que en primaria se tiene acceso a los libros de texto gratuito. Cabe plantear, a manera de hipótesis, que la base de los hallazgos de los estudios cualitativos son los libros de texto, a los que se considera material de estudio. Lo mismo sucede con otro tipo de libros que tampoco se legitiman como tales, entre ellos los de religión y los manuales que enseñan algún oficio o actividad manual.

En cuanto a los lectores que declararon haber leído libros en algún momento de su vida, pero que en el presente no lo hacen, pueden apreciarse rangos de edades y escolaridad donde las diferencias son menores, aunque no ocurre lo mismo en cuanto a las clases socioeconómicas. Por la manera en que está planteada la pregunta respectiva y por las repuestas, se podría pensar, de nuevo en términos de suposiciones, en un debilitamiento de la práctica de la lectura de libros, es decir de una tendencia al iletrismo, por las siguientes razones: 
- No hubo un arraigo de la práctica lectora y únicamente se leyeron libros con fines escolares, o alguna actividad específica.

- La institución escolar no propicia el gusto por la lectura.

- El acceso a los libros resulta difícil.

- El capital lingüístico es precario.

- Se leen libros no considerados como tales.

- La lectura de libros se relaciona con actividades escolares.

En cuanto a la frecuencia de lectura de libros, casi la tercera parte de quienes no acostumbran leer no lo han hecho ni como parte de sus actividades escolares o laborales.

\begin{tabular}{|c|c|c|}
\hline \multicolumn{2}{|c|}{ Libros leídos al año } & Ninguno \\
\hline \multicolumn{2}{|c|}{ Nacional } & 33.5 \\
\hline \multirow{2}{*}{ Sexo } & Hombre & 32.6 \\
\hline & Mujer & 34.2 \\
\hline \multirow{6}{*}{ Edad } & 12-17 años & 27.2 \\
\hline & 18-22 años & 22.0 \\
\hline & 23-30 años & 35.4 \\
\hline & 31-45 años & 32.2 \\
\hline & 46-55 años & 39.0 \\
\hline & 56 años o más & 48.3 \\
\hline \multirow{5}{*}{ Escolaridad } & Ninguna & 60.1 \\
\hline & Primaria & 48.5 \\
\hline & Secundaria & 34.5 \\
\hline & Bachillerato & 24.3 \\
\hline & Universidad o más & 16.0 \\
\hline \multirow{5}{*}{$\begin{array}{c}\text { Nivel } \\
\text { socioeconómico }\end{array}$} & Muy bajo & 50.7 \\
\hline & Bajo & 41.3 \\
\hline & Medio bajo & 31.4 \\
\hline & Medio & 15.3 \\
\hline & Medio alto/Alto & 11.1 \\
\hline
\end{tabular}

Fuente: Encuesta Nacional de Lectura. México: CONACULTA, 2006. p. 37

La encuesta aquí referida ha estimado también la frecuencia de la lectura de libros, según las relaciones de éstos con las actividades escolares o laborales o independientemente de ellas. 


\begin{tabular}{|c|c|c|c|c|}
\hline & Literatura General & Para la Escuela & Para el Trabajo \\
\hline & & $\begin{array}{c}\text { Nunca ha leído } \\
\text { No acostumbra leer }\end{array}$ & $\begin{array}{c}\text { Nunca ha leído } \\
\text { No acostumbra leer }\end{array}$ & $\begin{array}{c}\text { Nunca ha leído } \\
\text { No acostumbra leer }\end{array}$ \\
\hline \multicolumn{2}{|c|}{ Nacional } & 56.2 & \begin{tabular}{|l|}
44.8 \\
\end{tabular} & 87 \\
\hline \multirow{2}{*}{ Sexo } & Hombre & 11.7 & 43.9 & 81.1 \\
\hline & Mujer & 10.5 & 45.5 & 91.9 \\
\hline \multirow{6}{*}{ Edad } & 12-17 años & 7.5 & 15.5 & 94.4 \\
\hline & 18-22 años & 9.6 & 34.7 & 88.8 \\
\hline & 23-30 años & 11.3 & 48.2 & 82.9 \\
\hline & 31-45 años & 14.8 & 50.3 & 83 \\
\hline & 46-55 años & 11.1 & 62.6 & 84.3 \\
\hline & 56 años o más & 9.6 & 63.8 & 92.1 \\
\hline \multirow{5}{*}{ Escolaridad } & Ninguna & 0.4 & 68.9 & 98.7 \\
\hline & Primaria & 5.8 & 52.2 & 91.8 \\
\hline & Secundaria & 9.3 & 33.9 & 90.7 \\
\hline & Bachillerato & 14.6 & 44.7 & 83.3 \\
\hline & Universidad o más & 19.3 & $50.6 \mathrm{~s}$ & 75.6 \\
\hline \multirow{5}{*}{$\begin{array}{c}\text { Nivel } \\
\text { socioeconómico }\end{array}$} & Muy bajo & 4.1 & 41.4 & 94.4 \\
\hline & Bajo & 7.0 & 47.1 & 88.9 \\
\hline & Medio bajo & 13.5 & 41.8 & 86.3 \\
\hline & Medio & 15.7 & 49.8 & 83.6 \\
\hline & Medio alto/Alto & 22.1 & 43.1 & 72.5 \\
\hline
\end{tabular}

Fuente: Encuesta Nacional de Lectura. México: CONACUlTA, 2006. p. 31-33

\section{POCO LECTOR O LECTOR ESPORÁdICO DE LIBROS}

Conforme a los parámetros cuantitativos de la encuesta, el grupo poco lector o lector esporádico lo integran quienes respondieron que leen menos de tres libros al año y que prefieren leer otro tipo de materiales como diarios y revistas, así como quienes declararon que no les gusta leer o les gusta poco, reconocen que sus preferencias están orientadas también a la lectura de diarios o revistas.

\section{Libros le ídos al año}

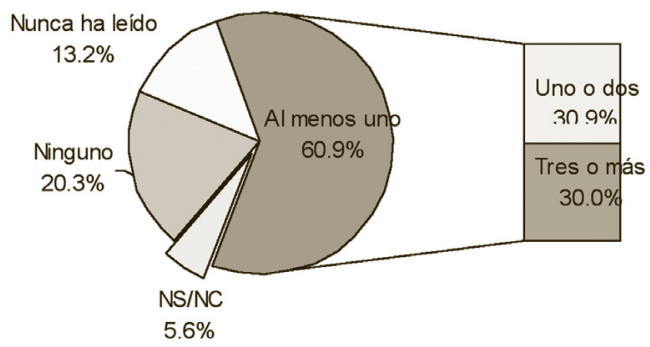

Fuente: Encuesta Nacional de Lectura. México: CONACULTA, 2006. p. 36 
En lo relacionado con el número de libros leídos en un año, los porcentajes varían ligeramente según la pregunta sobre si se leen o si han leído libros en algún momento de la vida.

\begin{tabular}{|l|c|c|c|c|c|c|c|}
\hline & $\begin{array}{c}\text { Nunca } \\
\text { ha } \\
\text { leído } \\
\text { libros }\end{array}$ & $\begin{array}{c}\text { No acostumbra } \\
\text { o acostumbraba } \\
\text { leer }\end{array}$ & $\begin{array}{c}\text { Diario o } \\
\text { varias } \\
\text { veces a la } \\
\text { semana }\end{array}$ & $\begin{array}{c}\text { Una } \\
\text { vez a la } \\
\text { semana }\end{array}$ & $\begin{array}{c}\text { Una 0 } \\
\text { algunas } \\
\text { veces al mes }\end{array}$ & $\begin{array}{c}\text { 0casional- } \\
\text { mente }\end{array}$ & Nc \\
\hline $\begin{array}{l}\text { Literatura en } \\
\text { general }\end{array}$ & 13.2 & 43.0 & 9.5 & 10.6 & 11.0 & 11.1 & 1.6 \\
\hline $\begin{array}{l}\text { Para la } \\
\text { escuela }\end{array}$ & 13.2 & 31.6 & 30.8 & 11.2 & 6.0 & 6.3 & 0.9 \\
\hline $\begin{array}{l}\text { Para el } \\
\text { trabajo }\end{array}$ & 13.2 & 73.8 & 3.4 & 3.6 & 4.0 & 1.8 & 0.2 \\
\hline
\end{tabular}

Fuente: Encuesta Nacional de Lectura. México: CONACULTA, 2006. p.37

Aunque la lectura de libros aumenta en la medida en que se eleva la escolaridad a partir de primaria, en el plano socioeconómico se registran pocas diferencias entre estratos sociales. Una de las causas de ello puede deberse a que, entre algunos lectores, la lectura de libros de texto y aun de literatura, que forma parte de las actividades escolares, se concibe como estudio; o bien a que no leen directamente libros, sino partes fotocopiadas de ellos, en especial cuando estudian en los niveles de enseñanza media y superior. Otra posibilidad es que recurran a apuntes de clase y, en la actualidad, a Internet, que en ciertas circunstancias remplaza el uso de libros.

En la tabla que sigue se aprecia el porcentaje referido a los libros de texto si consideramos que la población estudiantil que se encuestó corresponde a 12 años o más. Con relación al tema del olvido, en algunas investigaciones longitudinales se pidió a los encuestados que llevaran una bitácora de los libros leídos durante cierto periodo y posteriormente, cuando se les preguntó por los libros leídos, incurrieron en omisiones o refirieron títulos de libros que no fueron incluidos en dicha bitácora. ${ }^{14}$ En la tabla también se observa que el porcentaje de quienes no recuerdan el último libro leído es elevado, lo que quiere decir que el factor olvido reviste gran importancia. Entre los libros más mencionados aparece La Biblia, muy leída en las familias por adultos mayores y de diferentes clases sociales. También se leen con gran frecuencia estos títulos: Juventud en éxtasis y Juventud en éxtasis 2, Un grito desesperado y Volar sobre el pantano, todos ellos del mismo autor, Carlos Cuauhtémoc Sánchez, autor de esas novelas que abordan temas de superación personal y de orientación para entablar relaciones sentimentales; según 
la propaganda de estas obras, están dirigidas a públicos jóvenes y a padres de familia, además de que forman parte de las lecturas escolares. Otros libros muy gustados por los niños y adultos son los Cuentos de Cañitas, de Carlos Trejo, que comprenden relatos de terror. Entre los libros frecuentados, sorprende la ausencia de las letras mexicanas y en general hispanoamericanas, pese a contar con abundantes obras reconocidas por su calidad, excepto Don Quijote, que también es objeto de una lectura escolar y del que a menudo sólo se leen capítulos o versiones resumidas.

\begin{tabular}{|l|c|c|}
\hline \multirow{2}{*}{\begin{tabular}{c}
\multirow{2}{*}{$\begin{array}{c}\text { ¿Cuál fue el último libro que } \\
\text { leyó }\end{array}$} \\
\cline { 2 - 3 }
\end{tabular}} & $\begin{array}{c}\text { Sobre } 86.8 \% \text { que lee } \\
\text { 0 ha leído }\end{array}$ & Sobre 56.4\% que lee \\
\hline No recuerda & 51.0 & 38.8 \\
\hline Otros & 32.1 & 41.3 \\
\hline Libros de texto & 3.6 & 4.0 \\
\hline La Biblia & 2.6 & 2.3 \\
\hline Juventud en éxtasis & 1.2 & 1.4 \\
\hline Don Quijote de la Mancha & 0.8 & 0.9 \\
\hline El código Da Vinci & 0.7 & 1.1 \\
\hline Los hornos de Hitler & 0.7 & 0.2 \\
\hline El esclavo & 0.7 & 1.1 \\
\hline Un grito desesperado & 0.7 & 1.0 \\
\hline Cuentos de Cañitas & 0.7 & 0.6 \\
\hline El juego de la vida & 0.6 & 0.9 \\
\hline Volar sobre el pantano & 0.6 & 0.5 \\
\hline Superación personal & 0.6 & 0.9 \\
\hline Insuficientemente especificado & 0.5 & 0.7 \\
\hline El diario de Ana Frank & 0.5 & 0.8 \\
\hline Harry Potter & 0.5 & 0.6 \\
\hline El caballero de la armadura oxidada & 0.5 & 0.7 \\
\hline Aprender a ser joven & 0.4 & 0.7 \\
\hline Frankenstein & 0.4 & 0.6 \\
\hline El alquimista & 0.4 & 0.6 \\
\hline No leyó ningún libro & 0.2 & 0.3 \\
\hline & 100.0 & 100.0 \\
\hline
\end{tabular}

Fuente: Encuesta Nacional de Lectura. México: CONACULTA, 2006. p. 23

El promedio nacional de lectura es de 2.9 libros leídos, entre casi 60\% de la población que respondió a la pregunta sobre los libros leídos en un año, puesto que $43.1 \%$ de ella no leyó ninguno y $0.5 \%$ no sabe o no contestó. En cuanto a la categoría "poco lector" o "lector esporádico", tomamos a los grupos que leen entre uno y dos libros al año, que representan el 30.9\%. En cuanto a los tres grupos de lectores más asiduos, que leen de tres libros en 
adelante al año, es decir que se ubican por encima del promedio, éstos representan el $30 \%$. Esto puede considerarse un avance importante, pues para tales lectores leer un libro al año representa un esfuerzo considerable si se piensa en el capital lingüístico y cultural requerido para ello, que en sentido opuesto es capaz de influir en la falta de gusto o interés por la lectura. Lo mismo puede decirse de la disponibilidad de tiempo y, en algunos casos, las dificultades de acceso a libros y la reducida disponibilidad de éstos.

\section{¿Usted cree que ahora lee más o lee menos que antes?}

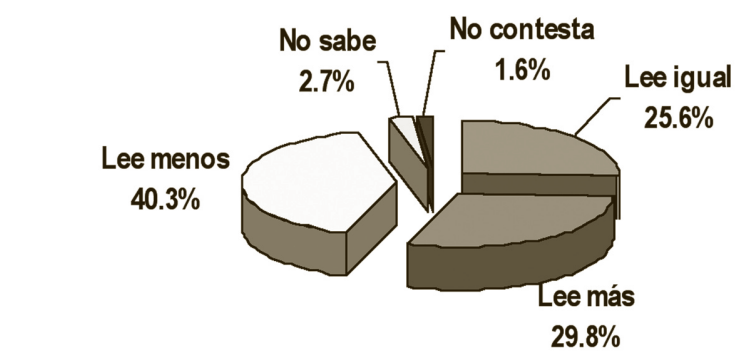

Fuente: Encuesta Nacional de Lectura. México: CONACULTA, 2006. p. 102

$\mathrm{Al}$ no disponerse de un referente anterior para saber si la trayectoria de lectura de libros tiende al fortalecimiento o al debilitamiento, y tomando en cuenta la respuesta de los encuestados que aparecen en la gráfica, cabe suponer que quienes leen para informarse son lectores de periódicos $(42 \%)$ y revistas (39\%) y que, como en el $40 \%$ de la muestra se observa una declinación en la lectura de libros, ello tal vez se relacione directamente con la razón principal por la que lee: informarse, pues la frecuentación de publicaciones periódicas actuaría en detrimento de la lectura de libros, y algo semejante ocurriría con la lectura realizada con fines escolares (20.5\% de la muestra). En cambio, quienes leen igual que antes $(25.6 \%)$ y más que antes $(29.8 \%)$ se relacionarían más con la lectura por gusto o entretenimiento (quienes la practican representan el 16\% de la muestra). Otras motivaciones para emprender la lectura, como la búsqueda de crecimiento personal y profesional, el deseo de llegar a ser culto, el afán de procurarse temas de conversación e intereses religiosos, alcanzan en conjunto el $18.4 \%$.

Por lo que respecta a la cantidad de libros leídos en un año, el grupo con estudios de bachillerato tiende a ser un lector esporádico, en tanto que el de estudiantes universitarios tiende a rebasar ese nivel. En la siguiente tabla, se observa una trayectoria progresiva del número de libros leídos conforme 
aumenta la escolaridad que corresponde a la edad de 12-22 años, en la cual se concentra la actividad escolar. No podemos determinar si en las generaciones siguientes se observa un menor número de libros leídos, ni si en relación con ellas se registra un trayecto de fortalecimiento o debilitamiento de la lectura ni tampoco si consideramos que se trata de generaciones con diferentes posibilidades de acceder a la lectura y a los libros.

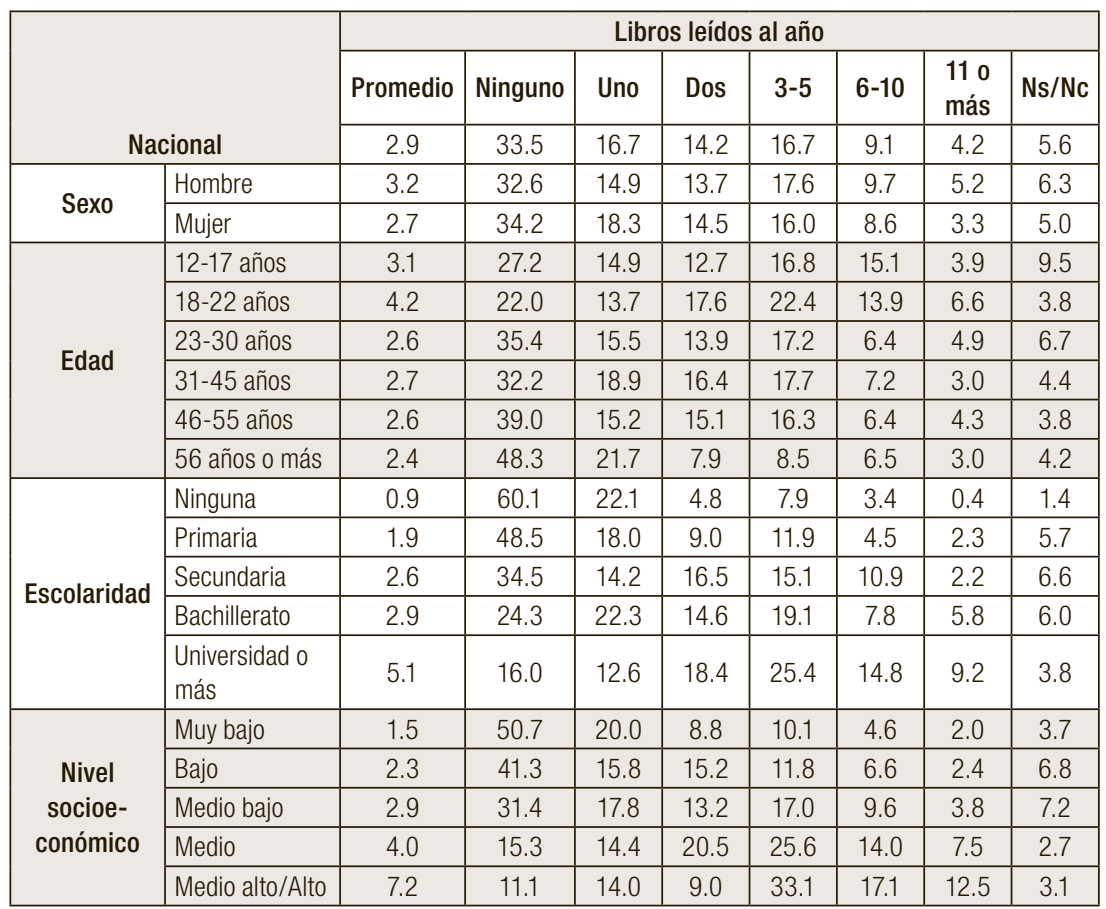

Fuente: Encuesta Nacional de Lectura. México: CONACUlTA, 2006. p. 37

En cuanto a las modalidades de lectura de libros, apreciamos en la siguiente gráfica que sólo el $46.7 \%$ de los lectores acostumbra leer libros completos. Además, entre miembros de las generaciones jóvenes es común advertir que la lectura se realiza simultáneamente con otras actividades, como ver televisión, escuchar música -en especial esto último, gracias a los nuevos artefactos pequeños que, no obstante serlo, permiten almacenar y reproducir grandes volúmenes de grabaciones- o realizar conversaciones telefónicas. Así, a menudo se observa que los jóvenes leen en las pantallas de las computadoras, al mismo tiempo que tienen puestos los audífonos, con el ipod colocado a un lado, o que dialogan mediante el teléfono celular. 


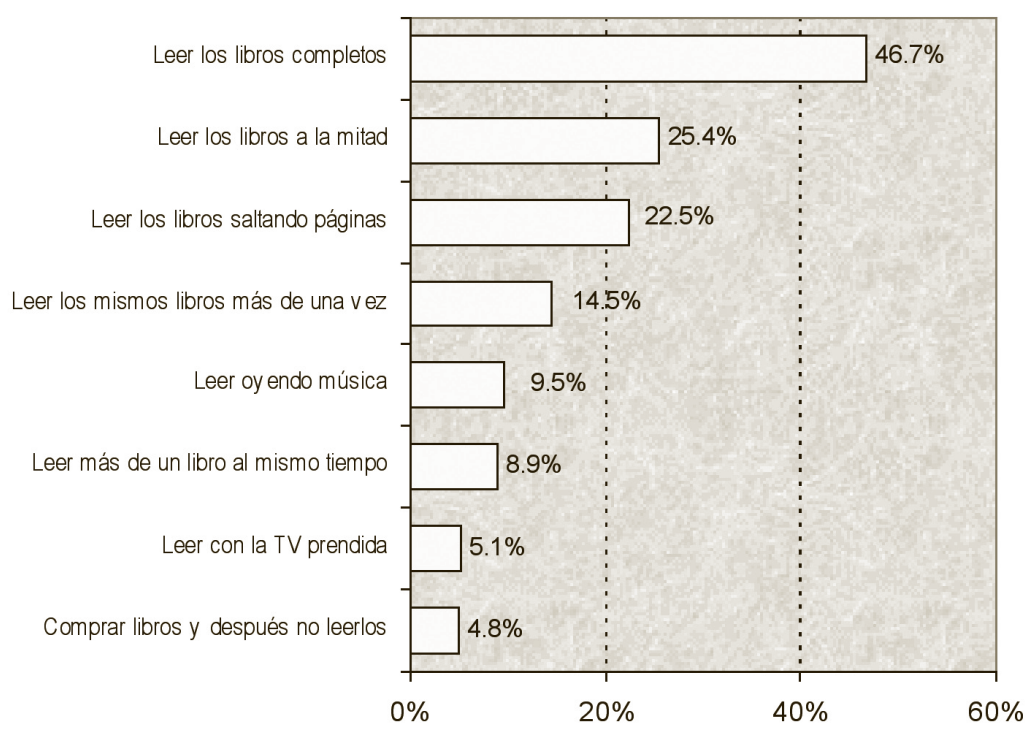

Fuente: Encuesta Nacional de Lectura. México: CONACUlTA, 2006. p.105

En cuanto al factor placentero de la lectura, las respuestas "me gusta mucho" y "me gusta leer" representan, respectivamente, el $15.4 \%$ y el $33.3 \%$ del total, lo cual, sumado, equivale a casi el 50\%. La otra mitad responde en sentido opuesto, "no me gusta" o "me gusta poco leer", como se observa en este cuadro:

\begin{tabular}{|c|c|c|c|}
\hline \multirow{3}{*}{\multicolumn{2}{|c|}{$\begin{array}{c}\text { En general } \\
\text { ¿cuánto le gusta leer? } \\
\text { Nacional }\end{array}$}} & & \multirow{4}{*}{$\begin{array}{c}\text { Me gusta poco } \\
36 \\
32.6\end{array}$} \\
\hline & & \multirow{3}{*}{$\begin{array}{c}\text { No me gusta } \\
15.3 \\
16.3\end{array}$} & \\
\hline & & & \\
\hline \multirow{2}{*}{ Sexo } & Hombre & & \\
\hline & Mujer & 14.5 & 38.8 \\
\hline \multirow{6}{*}{ Edad } & 12-17 años & 15.2 & 44.6 \\
\hline & 18-22 años & 13.1 & 25.6 \\
\hline & 23-30 años & 15.0 & 34.7 \\
\hline & 31-45 años & 14.8 & 39.3 \\
\hline & 46-55 años & 14.6 & 34.7 \\
\hline & 56 años o más & 20.3 & 32.1 \\
\hline
\end{tabular}

Fuente: Encuesta Nacional de Lectura. México: CONACULTA, 2006. p. 48 
Respecto a las razones que invocan las personas para "no leer", resulta interesante comparar los dos cuadros siguientes. En el primero, la pregunta se refiere al encuestado, en tanto que en el segundo se interroga a propósito de su percepción de los demás. Se aprecia que los motivos que impiden o desalientan la lectura cambian de lugar en ellos: en el primero, el principal obstáculo para leer es la "falta de tiempo", mientras que en la segunda gráfica tal explicación se sitúa en el quinto lugar; en tanto, la "falta de interés y flojera" aparece en primer lugar cuando la pregunta se refiere a otros, pero en lo personal se desplaza al sexto lugar. La respuesta "porque no me gusta leer" es la segunda razón, invocada por un tercio de los encuestados, y puede relacionarse con que la sigue, relativa a la preferencia por actividades recreativas que excluyen la lectura. Esto, a su vez, podría vincularse con la respuesta "porque [leer] es difícil y da pereza", pues, como señala Garbe, la lectura no es una actividad fácil ${ }^{15}$ y ello la coloca en desventaja respecto a otras oportunidades de entretenimiento que procuran gratificación fácil y más rápida a cambio de esfuerzos menores.

\section{¿Cuáles son las principales razones por las que usted no lee?}

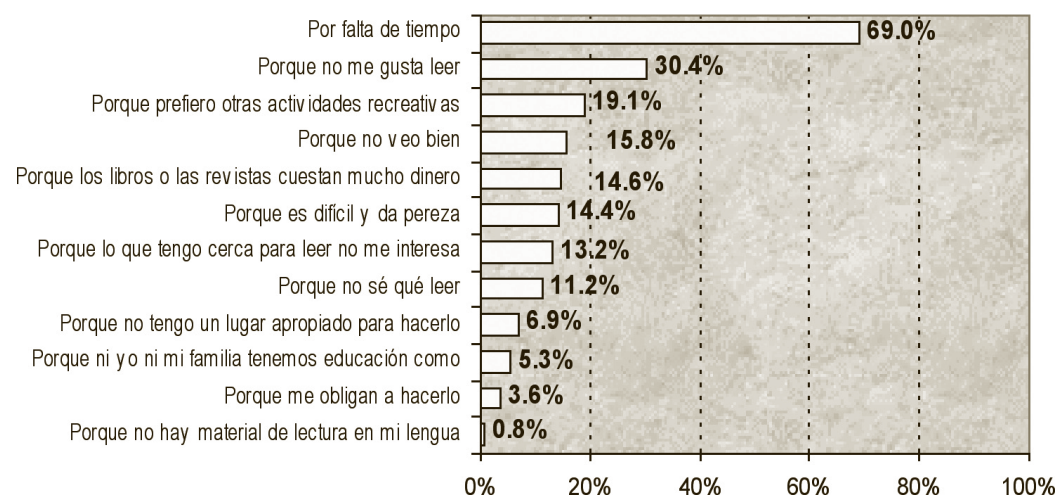

Fuente: Encuesta Nacional de Lectura. México: CONACUlTA, 2006. p. 43

15 Christine Garbe. Investigación de la lectura en Alemania. Métodos y resultados. En Seminario Lectura: pasado, presente y futuro. México: UNAM, CUIB, 2005. p. 150 


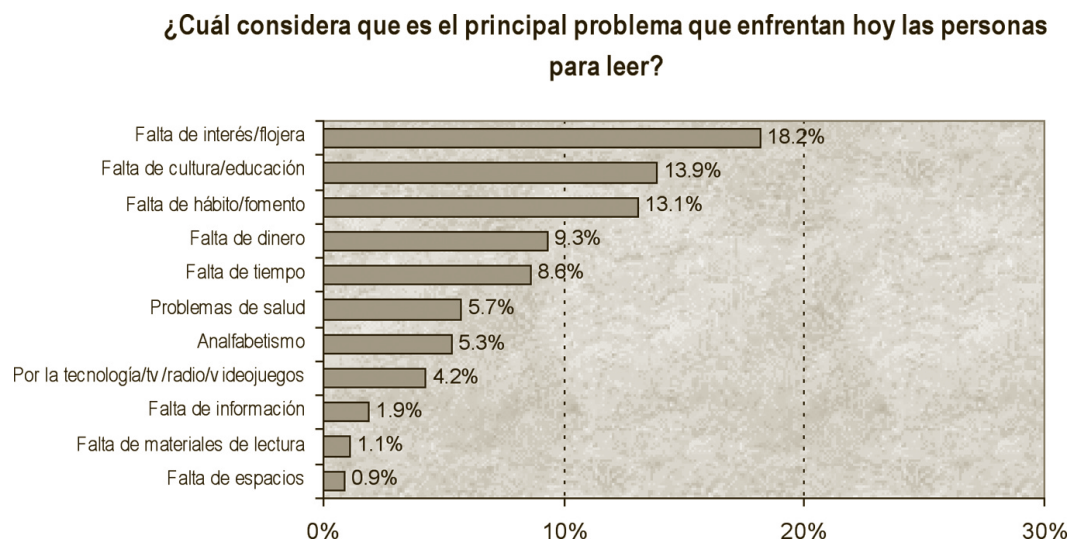

Fuente: Encuesta Nacional de Lectura. México: CONACULTA, 2006. p. 45

Otros factores importantes que impiden la práctica de la lectura, como se ve en los cuadros, son el costo de los libros y las revistas, la escasez de materiales de lectura disponibles y el desinterés que ellos inspiran. Si se considera que la biblioteca tiene por función precisamente reducir y hasta eliminar esos obstáculos para favorecer el acceso a una oferta gratuita, amplia y variada de obras, puede suponérsela ausente en el horizonte de los lectores. Aunque en un porcentaje menor, otra causa invocada para explicar que no se lee es la de que el encuestado se considere a sí mismo y a su familia inhabilitados para realizar la lectura por no contar con suficiente educación para ello. Si bien probablemente se trata de una mera excusa, también es posible interpretar esta respuesta como un mecanismo autoexcluyente, debido a reminiscencias de cierta concepción atávica de la cultura, según la cual el acceso a los libros y a la lectura se reservaría sólo a ciertas personas autorizadas. Llama la atención, sin embargo, que formulen tal respuesta tanto quienes cuentan con escolaridad primaria como egresados de universidades, y también miembros de la clase alta.

En la siguiente tabla (anexo 1), se observa de manera más pormenorizada que la respuesta "falta de tiempo", como explicación del hecho de que no se lea, guarda consistencia en todos los encuestados, aunque puede tratarse otra vez de una mera justificación para encubrir las causas verdaderas, que serían difíciles de asumir por corresponder a una actitud o una valoración negativas. Al respecto, no podemos eludir ciertas evidencias reconocidas hasta hace no muchas décadas, cuando la lectura de libros, placentera y cotidiana, la practicaban sectores privilegiados de la sociedad que, sin distinción de sexo y edad, disfrutaban de situaciones económicas holgadas, altos niveles de preparación, espacios adecuados y tiempo abundante para dedicarse a la lectura. Por otra 
parte, la oferta de entretenimiento era mucho más restringida y tendía a propiciar la actividad colectiva, incluso en el caso de la lectura, ya que ésta se compartía ampliamente por medio de conversaciones de distintos tipos centradas en autores, libros y temas. En la medida en que nuevos sectores sociales se han incorporado a la cultura escrita, en este caso con menos posibilidades de efectuar la lectura recreativa, han surgido prácticas que difieren de este modelo, lo cual coincide con un enorme crecimiento, hacia mediados del siglo pasado, de los medios masivos de comunicación: prensa, radio, cine y televisión, en medio de un nuevo escenario social donde impera la "civilización de la imagen", ${ }^{16}$ que relativiza la importancia y las funciones de los libros.

Gubern llama a ese proceso "la epifanía de la imagen digital", ${ }^{17}$ que transfigura las formas tradicionales de presentación icónica. Paralelamente a él, la tecnología digital ha revolucionado la relación con el tiempo y el espacio al reducir las distancias y facilitar la transmisión de voz, datos e imágenes. La interactividad mediante los sentidos ofrece nuevas posibilidades de comunicación, información, entretenimiento, aprendizaje y socialización que convierten al impreso en sólo un medio más entre una variada gama de ellos. De esa manera, hoy en día, la "falta de tiempo" ha dejado de ser en las sociedades modernas una excusa fácil y elegante para convertirse en un real impedimento de la lectura placentera y de muchas otras actividades cuya realización demanda otro ritmo, más pausado.

Por otra parte, las respuestas relativas al "no gusto" o "poco gusto" por la lectura confirman que ésta se transmite por lo general asociada con fines escolares, cuyo sentido obligatorio puede excluir el gusto por la lectura y, por tanto, el potencial carácter de entretenimiento de ésta. En efecto, los lazos con la lectura y el libro se anudan en la escuela, que viene a ser así, en nuestras sociedades, la formadora de lectores. La familia e, incluso, la biblioteca han delegado por completo en esa institución la responsabilidad de desempeñar tal función, porque además se ha extendido ampliamente la errónea creencia de que, al inducir a leer con fines escolares, se promueve, como un efecto natural, el gusto por la lectura; es decir, no puede considerarse que el gusto sea intrínseco al aprendizaje de la lectura. Pero tampoco sería justo afirmar que en todos los casos la lectura escolarizada mata o impide el gusto por la lectura, hay quienes llegan a encontrar el placer de leer a pesar de la severidad de la transmisión escolar. Los resultados de la encuesta aquí comentada y de otros estudios han puesto en evidencia lo contrario y por eso

16 Cfr. Román Gubern, Del bisonte a la realidad virtual. La escena y el laberinto, Barcelona, Anagrama, 1996. p. 108

17 Román Gubern, El eros electrónico. Madrid: Taurus, 2000, p. 187 
ya empieza a analizarse el papel de la familia en la transmisión del gusto por la lectura. Eso explica que en las siguientes gráficas se pongan en relación los vínculos entre los padres y el acceso a los libros durante la infancia, pues ello podría explicar los diversos niveles del gusto por la lectura. Conviene señalar, a este respecto, que en los últimos tiempos la práctica de la lectura que los padres realizan en voz alta para sus hijos tiende a incrementarse, en especial antes de que éstos comiencen a ir a la escuela.

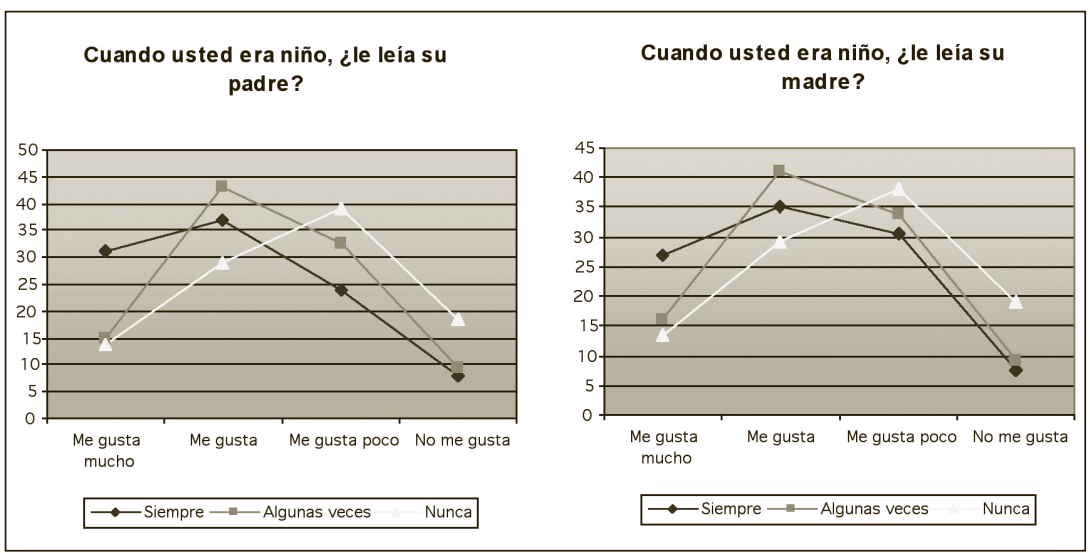

Fuente: Encuesta Nacional de Lectura. México: CONACULTA, 2006. p. 94

\section{Conclusiones}

En la actualidad, por fortuna, la lectura recobra su importancia. Por ello, con el propósito de observar el comportamiento lector de la sociedad, periódicamente se realizan encuestas al respecto. De igual manera, se intensifica el estudio de la lectura, incluso en un sentido cualitativo, con la finalidad de conocer con mayor profundidad, entre otros aspectos, la formación de las prácticas sociales relativas a ella, los problemas que obstaculizan el encuentro atinado entre sociedad y libros, y la efectividad de las acciones emprendidas por la escuela, la biblioteca, la familia y los organismos públicos y privados para mejorar dicho encuentro.

Las dos vertientes de la lectura y el libro, la educativa y la cultural, lejos de estar unidas por un lazo natural, como se creyó por muchos años, llegan a constituir fuerzas antagónicas, como ahora se sabe. Si bien promover el gusto por la lectura y desarrollar competencias lectoras no tendrían por qué ser tareas excluyentes, en la realidad ha sido difícil conciliarlas. Ya desde las primeras décadas del siglo XX han surgido reflexiones sobre la formación de 
prácticas de lectura vinculadas con tres fines: distraer, instruir e informar, en este orden, que no era casual, pues primero sería necesario dar a leer relatos que, a manera de carnadas y anzuelos, atraerían y atraparían a los lectores, los cuales transitarían posteriormente a las otras dos instancias. ${ }^{18}$ Sin embargo, la urgencia de formar y educar a los pueblos dio prioridad a la lectura instructiva e informativa y se dio por supuesto que más tarde ella alcanzaría por sí sola su sentido recreativo. De tal suerte, se instauraron representaciones y prácticas de lectura articuladas al proceso de enseñanza y aprendizaje, y la actividad lectora llegó a adquirir una elasticidad tan variable como un programa de alfabetización o el número de años que dura dicho proceso, el cual puede interrumpirse en algún momento entre la primaria y hasta en la educación superior.

Si consideramos que el promedio de escolarización en México alcanza 8.1 años (segundo año de secundaria), resulta evidente que tal proceso se interrumpe en los años de la adolescencia. Al respecto, Teresa Colomer señala que, hacia los 15 o 16 años, la mayoría de los adolescentes de los países occidentales abandona las aulas. Si los objetivos escolares se hubieran cumplido, todos ellos o por lo menos la mayoría, deberían ser lectores competentes en una sociedad alfabetizada, ${ }^{19}$ pero, como explica la misma autora, los estudios al respecto arrojan resultados poco halagüeños sobre tal supuesto. En realidad, la separación de la escuela a una edad temprana también suspende la actividad lectora obligatoria, y entonces puede suceder que, fuera del proceso educativo, la lectura de libros sea sustituida por la de otros medios que no se vinculan con deberes escolares ni suponen esfuerzo alguno que induzca a superar las competencias hasta entonces adquiridas. Desde luego, puede pensarse en los libros de literatura; sin embargo, al inscribirse su tratamiento en actividades escolares su enseñanza se ciñen a las técnicas pedagógicas utilizadas en los libros de texto y con frecuencia se sustraen al placer, lo cual propicia un debilitamiento de la práctica lectora de obras literarias, como lo prueba el alto índice de los no lectores y los lectores esporádicos de libros. Por tal motivo en los últimos años las políticas (planes nacionales) y leyes relacionadas con la lectura, el libro y las bibliotecas, pretenden fomentar la lectura de libros. ${ }^{20}$

Aunque según algunos estudios de los medios digitales hoy se lee más gracias a Internet, en la encuesta aquí considerada se encuentran datos de una trayectoria de lectura que indica que los porcentajes más altos de frecuencia

18 A. M. Chartier y J. Hébrard, Discursos sobre la lectura (1880-1980), España: Gedisa, 1994. p. 130

19 Teresa Colomer., Andar entre libros. La lectura literaria en la escuela. México: FCE, 2005, p. 65

20 Cfr. CERlalc. OEI, Ilímita, Plan Iberoamericano de Lectura [en línea] <http://www.cerlalc. org/ilimita/index.htm> 
de uso de la computadora corresponden a "diario" (10.0\%) y "varias veces a la semana" (9.8\%), y más de la cuarta parte de los encuestados $(26.6 \%)$ declaró usar la computadora al menos una vez a la semana. En el caso de internet, quienes tienen acceso a la red al menos una vez a la semana representan uno de cada cinco entrevistados (20.2\%). Entre el total de quienes aseguran usar la computadora todos los días, $28.5 \%$ lo hace de dos a tres horas y $34.1 \%$ más de cinco. Más de la mitad de los entrevistados, es decir el 50.4\%, declaró emplear la computadora para hacer tareas, porcentaje que, sumado al $33.8 \%$ que declaró utilizarla para estudiar, permite concluir que el uso más extendido tiene que ver con fines educacionales. La distracción ocupa también un lugar importante, pues a ella corresponde el $45.5 \%$ de las respuestas, lo mismo que el trabajo, que alcanza el $33.8 \%$ de ellas. El uso más importante es el correo electrónico, con más de la mitad de los usuarios (52.7\%). Si a ello se le suma el uso del chat $(44.7 \%)$, se advierte que la comunicación interpersonal es el principal fin con que se recurre a la Internet, seguido del estudio, que alcanza el $45.5 \%$. Esta última actividad incluye la investigación, aunque a menudo se limita a la copia y el pegado de textos para hacer tareas. El uso de la red con fines laborales llega al 29.3\%. Todo ello quiere decir que la lectura sostenida (realizada durante periodos largos y con profunda concentración), a la que se pretende vincular con formas de disfrute y entretenimiento no parece todavía producirse con ayuda de la red, dado que ésta exige una lectura más intermitente y rápida, realizada en textos breves, compactos, y, en ocasiones, elaborados mediante una escritura encriptada, como la usada por los jóvenes.

En México los indicios ofrecidos por la primera Encuesta Nacional de Lectura revelan el estado de esta última y dos dimensiones del desarrollo del país relativas a ella: una cercana a las economías desarrolladas y otra al subdesarrollo, como se ha evidenciado en las trayectorias de la lectura. Conforme a los datos cuantitativos, en los extremos se aprecian minorías: entre quienes declaran leer libros (56.4\% de los encuestados), el 12\% lee más de 6 libros y el $11.4 \%$ sólo 0.08 al año. Por otro lado, el 12.7\% de los entrevistados nunca ha leído libros. Aparte, el 30.4\% ha dejado de leerlos. En este último grupo se manifiesta un debilitamiento de la práctica de lectura de libros, es decir, una suerte de iletrismo, que se confirma con el tiempo que se lleva sin usar la biblioteca, en donde los libros son los principales materiales consultados (en $77.5 \%$ de los casos, en tanto otras colecciones se usan entre $1.4 \%$ y $8.2 \%$ ), el $77.25 \%$ de las veces para investigar y el $55 \%$ de ellas para estudiar. Las razones para no acudir de nuevo a la biblioteca son la falta de tiempo y el poco atractivo de la lectura ("no me gusta leer"). El acceso a los libros se obtiene así: en el $45.5 \%$ de los casos, mediante compra; en el 20.1\% 
por préstamos de familiares o amigos; en el 10.2\%, por préstamos de bibliotecas o salas de lectura. Además, el 54.3\% de los encuestados no ha comprado libros en el último año.

\begin{tabular}{|l|c|c|}
\hline $\begin{array}{c}\text { ¿Cuándo fue la última vez que } \\
\text { asistió a una biblioteca? }\end{array}$ & $\begin{array}{c}\text { De 66.4\% que } \\
\text { ha visitado una } \\
\text { biblioteca }\end{array}$ & $\begin{array}{c}\text { Porcentaje } \\
\text { sobre el total de } \\
\text { población }\end{array}$ \\
\hline Menos de 1 mes & 12.7 & 8.4 \\
\hline 1 a menos de 3 meses & 13.7 & 9.1 \\
\hline 3 a menos de 6 meses & 8.3 & 5.5 \\
\hline 6 a menos de 12 meses & 6.8 & 4.5 \\
\hline 1 año a menos de 3 años & 14.9 & 9.9 \\
\hline 3 años a menos de 5 años & 7.3 & 4.8 \\
\hline 5 años o más & 24.7 & 16.4 \\
\hline No sabe/No contesta & 11.6 & 7.8 \\
\hline No ha ido a una biblioteca & - & 33.6 \\
\hline \multicolumn{1}{|c|}{ Total } & 100.0 & 100.0 \\
\hline
\end{tabular}

Si se exceptúa el 44\% que no tiene escolaridad, la suma del conjunto de los no lectores de libros (los que nunca han leído y los que ya no leen), que alcanza el 43.6\%, más el de los lectores esporádicos, los poco lectores, que conforman el $30.4 \%$, nos permite suponer que la actividad educativa no propició las aptitudes o las actitudes, o ni unas ni otras, favorables para una trayectoria ascendente de lectura de libros ni para continuar una formación, tampoco para encontrar entretenimiento. Por otra parte, la biblioteca, tradicionalmente articulada a la lectura escolarizada, no ha tenido una participación social contundente para conmutar el debilitamiento de la trayectoria de la lectura. No obstante, ahora se busca modificar tal circunstancia mediante políticas de lectura, educación e información con las que se pretende preparar a los ciudadanos para adquirir herramientas de educación permanente y habilidades informativas. En consecuencia, se quiere considerar a la biblioteca, en especial la pública, como la responsable de rescatar, fortalecer y extender la práctica de la lectura asidua. Tal es el sentido de las siguientes recomendaciones de la Agenda de Políticas Iberoamericanas de Lectura suscritas por los gobiernos de la Organización de Estados Iberoamericanos:

- Diseñar e implementar, desde las bibliotecas, programas permanentes de promoción de lectura y escritura dirigidos a distintos grupos de la comunidad.

- Fortalecer los vínculos de las bibliotecas con otras entidades que promuevan las diferentes manifestaciones culturales.

- Crear y actualizar las bibliotecas escolares y otros espacios de lectura 
en las escuelas públicas, como instrumento indispensable en la formación de alumnos y maestros lectores y productores de textos.

- Formar a los docentes y a los bibliotecarios como auténticos lectores y escritores de tal modo que puedan ser mediadores efectivos de la lectura y la escritura.

- Desarrollar experiencias de formación y actualización, a través de las cuales los mediadores continúen su proceso de formación y se reconozcan como lectores y productores de textos.

- Incorporar la promoción de la lectura en los programas de formación profesional.

Asimismo, mediante diversas acciones emprendidas por las instituciones escolares y bibliotecarias, se intenta, por un lado, fortalecer los lazos de la familia con el impulso de la lectura placentera, puesto que de ello, como se ha visto, depende en buena medida el arraigo de la lectura asidua, y, por el otro, reconstruir las trayectorias que ocasionaron la escasa o esporádica lectura. Asimismo, se busca impedir el ensanchamiento de la franja del iletrismo y las nuevas formas de exclusión social y empobrecimiento intelectual y cultural derivadas de las deficiencias en el dominio de la lengua, que, en buena medida, es el efecto de modelos pedagógico obsoletos e indiferentes. No es extrañado que detrás del "no me gusta leer" se esconda el "me resulta difícil leer”, incluso en estudiantes de grados avanzados de escolaridad.

En suma, en México la poca lectura de libros es una trayectoria con dos sentidos, uno con dirección hacia la conformación de nuevos públicos que comienzan a escalar hacia prácticas de lectura más asiduas y por convicción. En dirección contraria públicos que han suspendido o disminuido la frecuencia de lectura de libros y se desvían hacia otras alternativas o bien, siguen la ruta del iletrismo, el cual no es un síntoma aislado sino resultado de las acciones institucionales del Estado, responsables de crear las condiciones que determinan la formación de representaciones y prácticas sociales de lectura. Por consecuencia, en las recomendaciones de los acuerdos dirigidos por impulsar la lectura, la biblioteca es considerada como una de las responsables de la transformación y el fortalecimiento de la actividad lectora de los ciudadanos, compromiso insoslayable pues los estudios y encuestas darán buena cuenta de su efectividad en el cambio de sentido del trayecto de la poca lectura. 


\section{BiBLIOGRAFÍA}

Bahloul, Joëlle, Lecturas precarias. Estudio sociológico sobre los "poco lectores”, México: FCE, 2002, p. 22

Chartier, Anne-Marie, and J. Hébrard, Discursos sobre la lectura (1880-1980), España, Gedisa, 1994, 583 p. (Lea; 1)

Chartier, Roger, El orden de los libros: lectores, autores y bibliotecas en Europa entre los siglos XIV y XVIII, Barcelona: Gedisa, 1994. 108 p.

Colomer, Teresa, Andar entre libros. La lectura literaria en la escuela, México: FCE, 2005. 280 p. (Espacios para la lectura)

Encuesta Nacional de Lectura / CONACUlTA, México: CONACUlTA, 2006, 287 p.

Garbe, Christine, "Investigación de la lectura en Alemania. Métodos y resultados", en Seminario Lectura: pasado, presente y futuro, México: UNAM, CUIB, 2005. pp. 128-159

Gubern, Román, El eros electrónico, Madrid: Taurus, 2000., 225 p.

McKenzie, D.F. Biblography and the Sociology of Texts, Londres: The British Library, 1986.,70 p.

Peroni, Michel, Historias de lectura. Trayectorias de vida y de lectura. México: FCE, 2003. 171 p. (Espacios para la lectura)

Petit, Michèle. Nuevos acercamientos a los jóvenes y a la lectura. México: FCE, 1999. 199 p. (Espacios para la lectura).

Thompson, John B. "La concepción simbólica y la concepción estructural de la cultura”, en Teoría y análisis de la cultura / comp. Gilberto Giménez Montiel, México: Universidad de Guadalajara, DGICSA, 1980, pp. 348-368. 


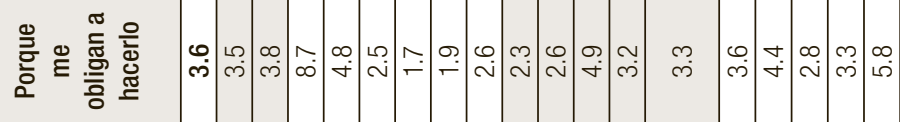

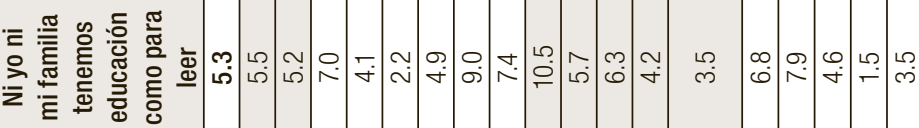

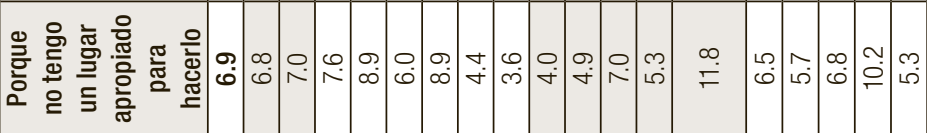

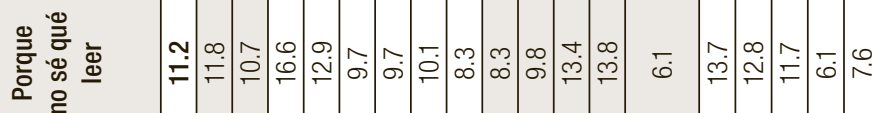

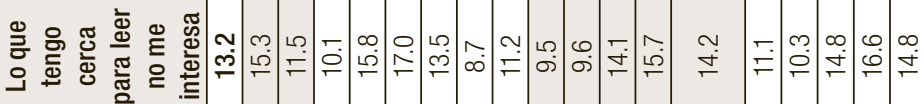

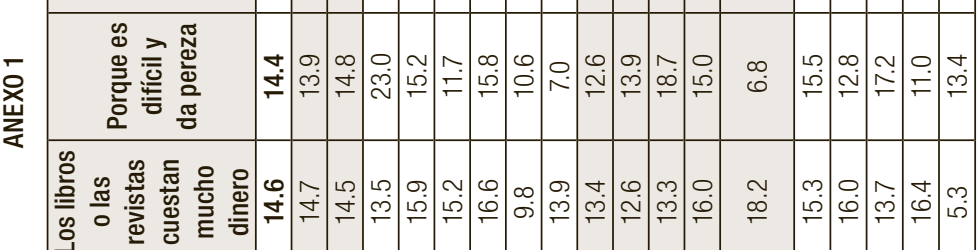

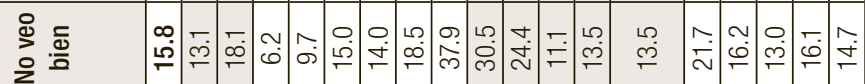

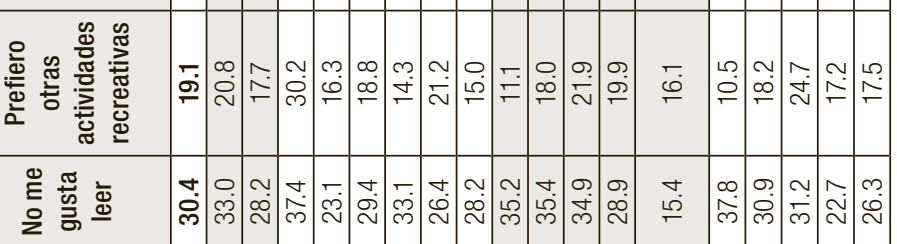

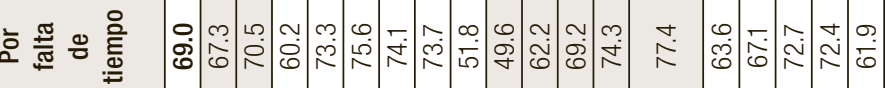

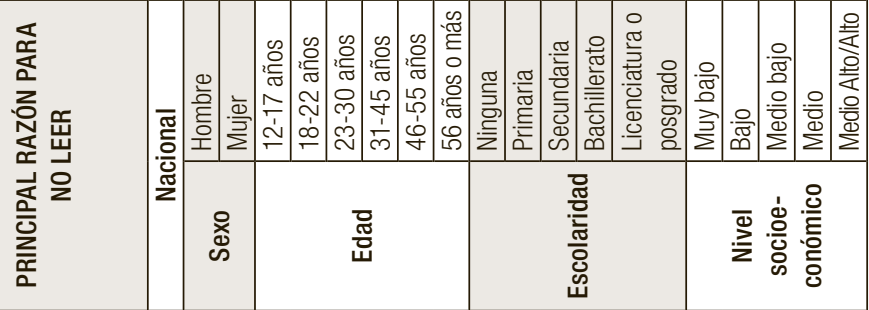

